\title{
Biliary-Pancreatic Endoscopic and Surgical Procedures in Patients under Dual Antiplatelet Therapy: A Single-Center Study
}

\author{
Ahmed Abdel Samie', Michael Stumpf ${ }^{2}$, Rui Sun ${ }^{1}$ and Lorenz Theilmann ${ }^{1}$ \\ Departments of ${ }^{1}$ Gastroenterology and ${ }^{2}$ Surgery, Pforzheim Hospital, Pforzheim, Germany
}

See commentary on page 315-316

\begin{abstract}
Background/Aims: Dual antiplatelet therapy has to be used for at least 1 month after placement of bare metal coronary stents and for a minimum of 1 year after placement of drug eluting stents. Because of the higher risk of bleeding, guidelines strongly recommend to delay elective surgery until dual antiplatelet therapy is ended. However, no data are available regarding the bleeding risk in patients on combined aspirin/clopidogrel therapy undergoing surgical or high-risk endoscopic procedures.
\end{abstract}

Methods: We retrospectively analyzed the medical reports of patients on dual antiplatelet therapy, the patients who had to undergo emergency biliary-pancreatic surgery or endoscopic retrograde cholangiography with endoscopic sphincterotomy while in our unit between January 2009 and July 2012.

Results: In our series, biliary-pancreatic surgical and endoscopic procedures were safely performed in 11 consecutive patients on dual antiplatelet therapy with no evidence of bleeding.

Conclusions: In emergency, surgical and high risk endoscopic procedures may be performed in patients on dual antiplatelet therapy.

Key Words: Dual antiplatelet therapy; Sphincterotomy, endoscopic; General surgery

\section{INTRODUCTION}

Despite the widespread use of dual antiplatelet therapy after coronary interventions, the optimal management of these drugs in patients undergoing surgical or endoscopic procedures is still unclear. Postsphincterotomy bleeding is one of the most frequent complications following endoscopic sphincterotomy (ES) and may occur in up to $10 \%$ of the patients. ${ }^{1}$ Use of anticoagulants within 3 days prior to the procedure is considered an additional risk factor for bleeding following ES. ${ }^{2}$ Therefore, the periprocedural management of anticoagulant and anti-

Received: October 18, 2012 Revised: November 18, 2012

Accepted: November 29, 2012

Correspondence: Ahmed Abdel Samie

Department of Gastroenterology, Pforzheim Hospital, Kanzler St 2-6, 75175 Pforzheim, Germany

Tel: +49-7231-969-3656, Fax: +49-7231-969-2682

E-mail: abdelsamie@ngi.de

(c) This is an Open Access article distributed under the terms of the Creative Commons Attribution Non-Commercial License (http://creativecommons.org/ licenses/by-nc/3.0) which permits unrestricted non-commercial use, distribution, and reproduction in any medium, provided the original work is properly cited. platelet therapy in this setting remains a common clinical problem.

Guidelines of the British Society of Gastroenterology ${ }^{3}$ and the American Society of Gastrointestinal Endoscopy ${ }^{4}$ recommend cessation of clopidogrel in patients on dual antiplatelet therapy 7 days prior to high risk endoscopic or surgical procedures. However, dual antiplatelet therapy has to be used in patients who received bare metal or drug eluting coronary stents. Discontinuation of this medication would strongly increase the risk for stent thrombosis with severe or even fatal consequences. Still, in few of these patients, emergency surgery, or high risk endoscopic interventions can become necessary, e.g., in the case of severe acute cholecystitis or septic cholangitis due to choledocholithiasis. As no data are available on the potential risk of bleeding in this setting, it was the aim of our study to report the outcome of our patients who underwent ES or biliary-pancreatic surgery while under dual antiplatelet therapy. 


\section{MATERIALS AND METHODS}

We retrospectively analyzed the medical records of all patients, who underwent biliary-pancreatic surgery or endoscopic retrograde cholangiopancreatography (ERCP) with ES in our hospital (Departments of Gastroenterology and Surgery, Pforzheim Hospital, Pforzheim, Germany) between January 2009 and July 2012. Pforzheim Hospital is a 500-bed, academic teaching, tertiary care hospital.

Patients under a dual antiplatelet therapy at the time of surgery/endoscopy were identified. Patient demographic, clinical, sonographic, endoscopic, surgical, and laboratory findings were collected. All patients in the endoscopic group underwent therapeutic ERCP with ES and basket/balloon stone extraction using a standard duodenoscope and standard sphincterotome-based technique on a guide wire (ERBE, Endocut mode: fractionated cutting mode characterized by alternating cutting and coagulation cycles). Patients undergoing biliary-pancreatic surgery while under dual antiplatelet therapy during the study period were also included.

\section{RESULTS}

Between January 2009 and July 2012, 11 patients (seven male and four female) were included in our study. The mean age of the patients was 60 years, with the youngest patient being 34 years old and the oldest 85 years (characteristics of the patients are shown in Table 1).

All patients were on continuous dual antiplatelet therapy with clopidogrel and aspirin due to either recently implanted bare metal or drug eluting coronary artery stent. The mean duration of this medication was 40 days with all patients catagorized as having high thrombotic risk.

Nine patients underwent endoscopic retrograde cholangiography with ES and basket/balloon stone/sludge extraction. In one patient, emergency cholecystectomy due to severe cholecystitis was performed. One patient underwent pylorus preserving pancreaticoduodenectomy due to recurrent bleeding from a duodenal diverticulum despite repeated endoscopic hemostasis.

ES was performed within 48 hours after admission in all patients. Indication for endoscopic therapy was lithogenic pancreatitis with cholestasis/cholangitis in three patients. Five patients underwent ERCP due to a high clinical suspicion of choledocholithiasis with cholangitis and one patient because of severe cholestasis (bilirubin $14 \mathrm{mg} / \mathrm{dL}$ ) due to a pancreatic head mass causing biliary obstruction.

Neither immediate nor clinically significant delayed postsphincterotomy bleeding occurred in any patient in the endoscopic group. In the two patients who underwent surgery, no perioperative bleeding was observed and no intraoperative transfusion of packed red cells was necessary.

There was no significant change in the hemoglobin levels before and after the procedure (mean hemoglobin $12.6 \mathrm{~g} / \mathrm{dL}$ vs. $12.2 \mathrm{~g} / \mathrm{dL})$.

\section{DISCUSSION}

Coronary stenting has become an established treatment of ischemic heart disease. Current guidelines ${ }^{5}$ recommend the

Table 1. Patients Characteristics

\begin{tabular}{|c|c|c|c|c|}
\hline Sex/Age & $\begin{array}{l}\text { Indication of dual } \\
\text { antiplatelet therapy }\end{array}$ & $\begin{array}{l}\text { Biliary-pancreatic } \\
\text { procedure }\end{array}$ & $\begin{array}{l}\text { Indication of surgical/ } \\
\text { endoscopic procedure }\end{array}$ & $\begin{array}{l}\text { Periprocedural transfusion } \\
\text { of packed red cells }\end{array}$ \\
\hline $\mathrm{M} / 58$ & DES & PPPD & $\begin{array}{l}\text { Severe bleeding from a duodenal } \\
\text { diverticulum }\end{array}$ & No \\
\hline $\mathrm{M} / 56$ & DES & Cholecystectomy & Severe cholecystitis & No \\
\hline $\mathrm{F} / 66$ & DES & ES and biliary stenting & $\begin{array}{l}\text { Severe cholestasis due to a pancratic } \\
\text { head mass }\end{array}$ & No \\
\hline $\mathrm{M} / 66$ & DES & ES and stone extraction & Biliary pancreatitis with cholangitis & No \\
\hline $\mathrm{M} / 34$ & DES & ES and stone extraction & Biliary pancreatitis with cholangitis & No \\
\hline $\mathrm{F} / 75$ & BMS & ES and stone extraction & Biliary pancreatitis with cholangitis & No \\
\hline $\mathrm{M} / 68$ & DES & ES and stone extraction & Choledocholithiasis/cholangitis & No \\
\hline $\mathrm{F} / 42$ & DES & ES and stone extraction & Choledocholithiasis/cholangitis & No \\
\hline $\mathrm{M} / 81$ & BMS & ES and stone extraction & Choledocholithiasis/cholangitis & No \\
\hline $\mathrm{M} / 65$ & DES & ES and stone extraction & Choledocholithiasis/cholangitis & No \\
\hline $\mathrm{F} / 85$ & BMS & ES and stone extraction & Choledocholithiasis/cholangitis & No \\
\hline
\end{tabular}

M, male; DES, drug eluting stent; PPPD, pylorus preserving pancreaticoduodenectomy; F, female; ES, endoscopic sphincterotomy; BMS, bare metal stent. 
use of dual antiplatelet therapy for at least 1 month after placement of bare metal stents and at least 1 year after placement of drug eluting stents. Discontinuation of antiplatelet therapy was the most powerful predictor of drug eluting stent thrombosis in a prospective study including 3,021 patients. ${ }^{6}$

However, the risk of gastrointestinal bleeding may increase by 2 to 3 folds in patients on aspirin and clopidogrel compared with aspirin alone. ${ }^{7}$ Data regarding the management of combined antiplatelet therapy in patients undergoing surgical or endoscopic procedures are limited and current guidelines dealing with this common clinical scenario are mainly based on expert opinion.

Chernoguz et al. ${ }^{8}$ showed a significant increase in the risk of perioperative bleeding in patients using clopidogrel within 7 days of abdominal surgery. However, in a recently published case series of seven consecutive patients undergoing major abdominal surgery while under dual antiplatelet therapy, no serious bleeding complications occurred. ${ }^{9}$ The same authors reported on a patient undergoing successful liver transplantation with continued dual antiplatelet therapy without major bleeding complications..$^{10}$

In our series, two patients underwent urgent biliary-pancreatic surgery while under dual antiplatelet therapy without bleeding complications. There was no need of intraoperative blood transfusion in both cases.

The incidence of bleeding following gastrointestinal endoscopy varies depending on the procedure.

High-risk endoscopic procedures which may be associated with increased incidence of bleeding include polypectomy, ES, endoscopic mucosal resection, endoscopic submucosal dissection, dilation of strictures, percutaneous endoscopic gastrostomy, and endoscopic ultrasound-guided fine needle aspiration. ${ }^{3,4}$

In patients on dual antiplatelet therapy, clopidogrel should be stopped 7 days prior to high risk procedures, while aspirin can be continued. ${ }^{3}$ However, before stopping clopidogrel in high risk conditions, such as recently implanted drug eluting stents, consultation with the patient's cardiologist is mandatory. As a general principle, the risk of thromboembolism needs to be balanced against the risk of bleeding during an endoscopic interventional procedure.

The risk of bleeding under dual antiplatelet therapy was studied prospectively in patients undergoing transbronchial biopsies, yet the study was stopped early because of severe bleeding in both the clopidogrel alone and combined aspirin/ clopidogrel group compared to controls. Bleeding occurred in all patients (12 patients, moderate bleeding in six cases and severe bleeding in six cases) on uninterrupted dual antiplatelet therapy. ${ }^{11}$

In a retrospective case-control study including 118 patients, who underwent polypectomy while on clopidogrel, no increased risk of bleeding in this group could be detected. The authors concluded that the thrombotic risk of discontinuing clopidogrel prior to colonoscopy may exceed the risk of postpolypectomy bleeding (PPB). ${ }^{12}$

In another retrospective case-control study including 142 patients on clopidogrel (375 polypectomies) and 1,243 controls (3,226 polypectomies), the risk of PPB was significantly higher in patients undergoing the procedure while on clopidogrel and concomitant aspirin/nonsteroidal anti-inflammatory drugs. However, clopidogrel alone was not an independent risk factor for PPB, and the authors concluded that routine cessation of clopidogrel prior to colonoscopy/polypectomy is not necessary. ${ }^{13}$

Although unproven, prophylactic clip application may help to minimize the bleeding risk following polypectomy. Loop ligation or submucosal injection of diluted adrenaline may also have a protective role.

The evidence for increased risk of postsphincterotomy bleeding under aspirin is unclear, yet current guidelines suggest that ES may be performed in patients taking aspirin in the absence of pre-existing bleeding disorders. ${ }^{3,4}$ There are no published data on the risk of hemorrhage with thienopyridine (clopidogrel, prasugrel, and ticlopidine) usage in patients undergoing ES.

A case-control retrospective study, including 40 patients and 86 controls, demonstrated that antiplatelet agents do not significantly increase the risk of clinically relevant bleeding following ES; however, due to the limited number of patients on clopidogrel (one patient in the case group) in this study, no definitive recommendation regarding the use of clopidogrel in patients undergoing ES can be made. ${ }^{14}$

In contrast to the increased risk of bleeding in the setting of transbronchial biopsies under dual antiplatelet therapy as shown by Ernst et al., ${ }^{11}$ in our retrospective analysis, ES was performed safely in nine consecutive patients on uninterrupted combined antiplatelet therapy. Neither endoscopically relevant immediate nor clinically significant delayed bleeding was observed. The widely used Endocut mode in ES with alternating cutting and coagulation cycles may reduce the bleeding risk during ES compared to transbronchial biopsies.

Pure cutting current during ES should not be used in these patients, as the risk of bleeding is significantly increased as compared to blended current. Endoscopic papillary ballon dilation may represent an alternative to ES in patients with a high bleeding risk. However, the procedure is associated with increased risk of post-ERCP pancreatitis. ${ }^{15}$

We recognize that our study has several limitations. The study was retrospective in nature and includes a small number of cases; hence, further prospective studies with a larger num- 
ber of patients are needed to confirm our results.

However, this is the first study on the bleeding risk under dual antiplatelet medication in the setting of biliary-pancreatic surgical or endoscopic procedures, and despite the small number of patients in this study, we could demonstrate that at least in emergency, biliary-pancreatic surgical and endoscopic procedures may be performed safely in patients under dual antiplatelet drugs without increased bleeding risk.

Despite the wide-spread usage of dual antiplatelet therapy, no data are available regarding the bleeding risk in patients on combined aspiring/clopidogrel therapy undergoing biliarypancreatic surgical or endoscopic procedures.

In our series, ES and biliary-pancreatic surgery were safely performed in 11 patients on uninterrupted dual antiplatelet therapy with no evidence of perioperative or postsphincterotomy bleeding. To our knowledge, this is the first report on the safety of biliary-pancreatic surgical and endoscopic procedures in patients under dual antiplatelet therapy.

\section{Conflicts of Interest}

The authors have no financial conflicts of interest.

\section{REFERENCES}

1. Joyce AM, Kochman ML. Update on biliary endoscopy. Curr Opin Gastroenterol 2005;21:354-358.

2. Ferreira LE, Baron TH. Post-sphincterotomy bleeding: who, what, when, and how. Am J Gastroenterol 2007;102:2850-2858.

3. Veitch AM, Baglin TP, Gershlick AH, et al. Guidelines for the management of anticoagulant and antiplatelet therapy in patients undergoing endoscopic procedures. Gut 2008;57:1322-1329.

4. ASGE Standards of Practice Committee, Anderson MA, Ben-Menachem T, et al. Management of antithrombotic agents for endoscopic procedures. Gastrointest Endosc 2009;70:1060-1070.

5. King SB 3rd, Smith SC Jr, Hirshfeld JW Jr, et al. 2007 Focused update of the ACC/AHA/SCAI 2005 guideline update for percutaneous coronary intervention: a report of the American College of Cardiology/American Heart Association Task Force on Practice Guidelines: 2007 Writing Group to Review New Evidence and Update the ACC/AHA/SCAI 2005 Guideline Update for Percutaneous Coronary Intervention, Writing on Behalf of the 2005 Writing Committee. Circulation 2008;117:261-295.

6. Airoldi F, Colombo A, Morici N, et al. Incidence and predictors of drug-eluting stent thrombosis during and after discontinuation of thienopyridine treatment. Circulation 2007;116:745-754.

7. Abraham NS, Hlatky MA, Antman EM, et al. ACCF/ACG/AHA 2010 expert consensus document on the concomitant use of proton pump inhibitors and thienopyridines: a focused update of the ACCF/ACG/ AHA 2008 expert consensus document on reducing the gastrointestinal risks of antiplatelet therapy and NSAID use. Am J Gastroenterol 2010;105:2533-2549.

8. Chernoguz A, Telem DA, Chu E, Ozao-Choy J, Tammaro Y, Divino CM. Cessation of clopidogrel before major abdominal procedures. Arch Surg 2011;146:334-339.

9. Quante M, Benckert C, Thelen A, Kaisers U, Jonas S. Major abdominal surgery with continued dual antiplatelet therapy. Arch Surg 2011;146: 1334-1335.

10. Spieker H, Benckert C, Quante M, et al. Successful liver transplantation with continued dual antiplatelet therapy. Ann Transplant 2012;17:127130.

11. Ernst A, Eberhardt R, Wahidi M, Becker HD, Herth FJ. Effect of routine clopidogrel use on bleeding complications after transbronchial biopsy in humans. Chest 2006;129:734-737.

12. Feagins LA, Uddin FS, Davila RE, Harford WV, Spechler SJ. The rate of post-polypectomy bleeding for patients on uninterrupted clopidogrel therapy during elective colonoscopy is acceptably low. Dig Dis Sci 2011; 56:2631-2638.

13. Singh M, Mehta N, Murthy UK, Kaul V, Arif A, Newman N. Postpolypectomy bleeding in patients undergoing colonoscopy on uninterrupted clopidogrel therapy. Gastrointest Endosc 2010;71:998-1005.

14. Hussain N, Alsulaiman R, Burtin P, et al. The safety of endoscopic sphincterotomy in patients receiving antiplatelet agents: a case-control study. Aliment Pharmacol Ther 2007;25:579-584.

15. Boustière C, Veitch A, Vanbiervliet G, et al. Endoscopy and antiplatelet agents. European Society of Gastrointestinal Endoscopy (ESGE) Guideline. Endoscopy 2011;43:445-461. 